\title{
Ecological aspects of servicing transport infrastructure in megacities
}

\author{
Elena Stupnikova ${ }^{1, *}$ \\ ${ }^{1}$ Moscow State University of Railway Engineering. 127994, Moscow, 9/9 Obraztsova Street
}

\begin{abstract}
The article reviews the changes in approaches to planning and development of transport infrastructure in the world in connection to urbanization. By comparing statistical data for certain historical periods it is demonstrated that correctly drawn up approaches of transport infrastructure surveying affect GDP and growth of living standards and income level of megacities' dwellers.
\end{abstract}

\section{Introduction}

Transport infrastructure survey is an opinion poll and integrated expert evaluation of entire city infrastructure somehow connected with transport and traffic flows.

The survey results in framing of the system-based approach to development and management of transport infrastructure (general, strategic, and operational). Therefore ecological aspects of transport infrastructure survey of a megacity are part of integrated expert evaluation, development and management of transport infrastructure impact on megacity development.

Numerous studies have been published on environmental effects of the cities [1,2]. Over the last 100 years city planning and ecology have been affected by the attempts to mitigate assumed implications of such large-scale urbanization processes as environmental degradation and growth of adverse ecological effects in the cities. Before we review the aftermaths of transport infrastructure for megacity environment, it is worth throwing brief light on the roots of the "Eco-city" phenomenon.

\section{Historical and conceptual perspectives. Literature review}

At some point the industrialization molded the Dickensian squalor cities: dirty, blanketed with smoke, infested with diseases. By early XXth century numerous scholars had been looking for ways of improving living and working conditions in such industrial cities, e.g. Robert Kargon and Arthur Molella [3]. Kargon and Molella called their cities "Techno-cities" - i.e. cities where major industrial and technological enterprises existed along with gardens, flour mills and churches.

These early concepts of the cities have undoubtedly influenced the development of a modern "Eco-city", which has its own distinctive features and history. The term "Eco-city"

\footnotetext{
* Corresponding author: stupnikovaea@yandex.ru
} 
emerged relatively recently in 1980's when it was used in the context of growing environmental movement, in particular in "Eco-city Berkeley", one of the first publications of R. Register [4].

Richard Register is rightly considered to be the founder and emissary of eco-builders, one of the greatest theoreticians and authors of ecological design and city planning. For forty years he had been introducing his ideas into environmental context of local city projects. His concept consists of his ideas about urban development, transport, accommodation, economic development and social justice [5].

All emerging theories of eco-cities and movements had finally led to the first international eco-city conference held in Berkeley (California) in 1990.

Barton [6] noted that initially in the realization of eco-cities ideas there existed a significant gap between aspirations and actual achievements affected by various economic, political and social limitations interfering with development of the cities fighting to protect the environment.

In Russia D.Kavtaradze, A.Brudny, V.Agavelov, et al. introduced the concept of "Ecopolis" in 1980s [7].

"Earth Summit" held in Rio de Janeiro under the umbrella of the United Nations in 1992 marked the new stage in discussions about environment protection in megacities and shaped the terms of reference for eco-cities concepts [8].

As far as the transport system integrated into the eco-city is concerned, it was initially proposed by J.Macedo in the early 1980's [9].

M.Laituri [10] (New Zealand, 1996) made a name for herself with her attempt to integrate the Western concepts of managing transport systems in the context of eco-cities development [11].

\section{Materials and methods}

We studied the ecological aspects of transport infrastructure survey drawing on the example of Moscow, Cairo, and Rio de Janeiro. For comparison, statistical and historical information was used. For the sake of analyzing specific data absolute statistical values and megacity development models were reviewed against the background of long-term historical periods.

Both in Moscow and many other cities, especially in developed countries, the question of transport infrastructure survey finds itself at the intersection of multiple managerial, organizational and financial issues. The urbanization began in the developed countries and then migrated to poor and developing world.

Moscow as a city has begun thinking about its state of environment since 1920's, since general city plans of Moscow developed by B.Sacculin (1923) and S.Shestakov (1928) [12].

A relatively long period had passed, when the issues of Moscow greening had somehow been raised, before the decision was made to protect the urban green belt (parks, recreational forests, meadows, public gardens, boulevards), which played the critical role in further creation of the megacity and development of its transport infrastructure in the XXIst century.

Transport infrastructure and transport itself substantially contribute to pollution in the megapolis. More than 12.6 million tons of hazardous cancerogenic substances are emitted annually only in major Russian cities, therefore it is a complex task to form and develop megacities taking environment into account. In Moscow motor transport accounts for $93 \%$ of hazardous emissions [13].

In Moscow the population density is 107.3 people per hectare, higher than in major megacities of the world. For instance, the population density in Paris is 49 people per hectare and in London - 54 people per hectare [14]. 
The density of road network in Moscow is $3.38 \mathrm{~km} / \mathrm{sq} . \mathrm{km}, 2-4$ times lower than such indices in major world capitals. In Troitsky and Novomoskovsky districts the road network density is $0.88 \mathrm{~km} / \mathrm{sq} . \mathrm{km}$ [14].

The situation with traffic density on Moscow motorways is still worse, the traffic capacity being exceeded by $42 \%$ [15].

In spite of the excessive traffic capacity of the road network Moscow people prefer personal vehicles as means of transportation, thereby contributing to significant additional environmental problems.

New Moscow city plans envision significant expansion of the road network up to $500 \mathrm{~km}$ by 2017 as well as hundreds of multi-purpose terrace parks, being built and planned to be built along Moscow river embankment and in the city itself. Intensive activities with a view to limiting motor vehicles traffic within Garden Ring through effective use of parking space are underway.

Since 2013 to $2020350-550$ billion rubles have been and will have been invested annually into Moscow transport infrastructure development [14], Fig.1.

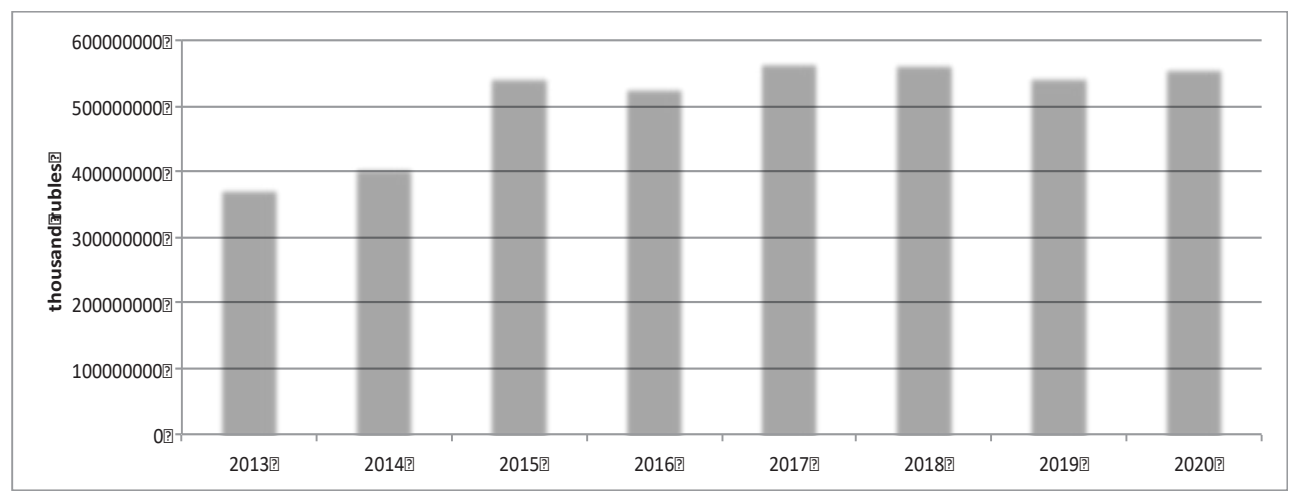

Fig. 1. Expenditures on Moscow transport infrastructure development.

Environmental aspects of transport infrastructure development are subject to political decisions taken in various countries. In this case new paradigm of transport infrastructure development of megacities can be a part of a solution to reverse the worsening situation: a city should be developed for the sake of people not vehicles.

Rapid urbanization - is the biggest structural transformation of the XXIst century. The development of transport in megacities within next several decades will be reflecting the sharp urban population growth, especially in the developing countries.

The world urban population will have increased by 2.8 billion people by $2050.96 \%$ of them will live in the countries with low or medium income [11]. Entire population of world megacities will be 4 billion people.

The number of world megacities with population over 10 million people is expected to reach 37 by 2025 , i.e. twice as many as in 2000 . By 2025 over 2.1 billion people will have lived in million-plus cities [11].

The cities have become the engine of economic development in the world. The processes of transport development are integrated into urbanization process, which in its turn is an integral part of the evolution. No economically developed country has missed a process of urbanization. This explains and attests to the correlation between rate of urbanization, economic growth and transport development planning. For example, Greater Cairo produces $50 \%$ of Egypt's GDP. In Brasil states of Rio de Janeiro (where city of Rio de Janeiro is located) and Minas Gerais account for over $52 \%$ of the national GDP. 


\section{Results}

The development and construction of infrastructure are planned in megacities for dozens of years to come. Chronic excessive traffic capacity of motorways is estimated to be an equivalent of $3 \%$ drop of GDP, has negative impact on water supply, sewage, habitat, and public health care. And finally the cities transport system is one of the main causes of pollution, carbon emissions and excess power demand.

We have established that the green paradigm, increasingly used in planning and development of transport infrastructure, insists that today the megacity development should go hand in hand with sustainable economic growth and mitigation of pollution of environment. Transport infrastructure economics is associated with fragmentary management. The management is fragmentary since different services and agents within one city solve different issues at different levels of government. Such a fragmentation limits complex and integrated economic planning, leads to lack of coordination and economic inefficiency. The transport infrastructure survey today means effective management of municipal transport infrastructure, which calls for several broad-ranging skills: consolidation of broad range of entities, consolidation of construction operations, land distribution, planning, environmental protection and traffic control (Fig. 2).

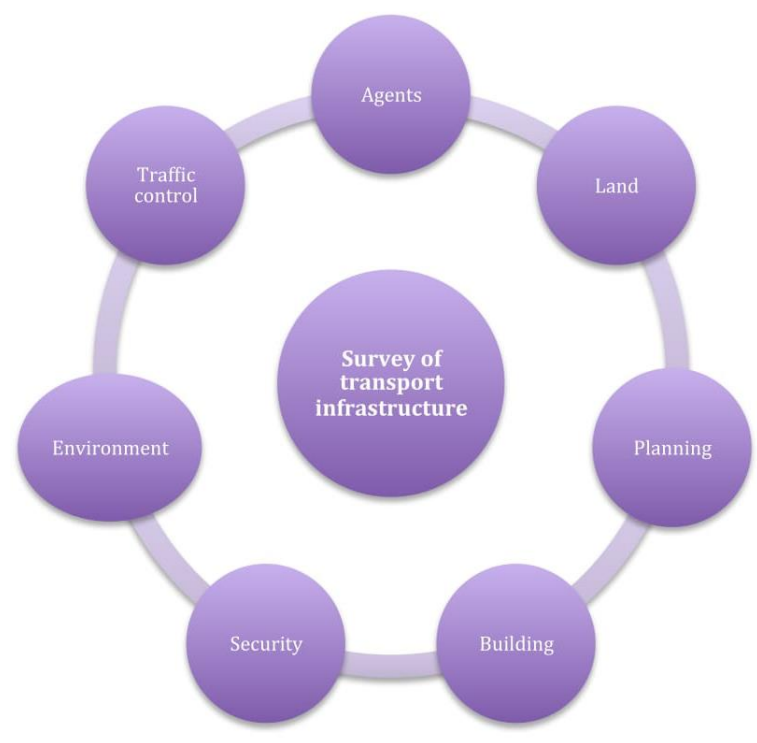

Fig. 2. The megacity transport infrastructure survey.

The transport infrastructure survey today means the development of effective systems of city transport. Transport provides access to job sites, education, health care and other social functions. However increased mobility is achieved at a certain cost, such as slower rate of traffic in downtown parts of the city, longer travelling time. For instance, more than $20 \%$ of working population in Mexico City spend over three hours to get to their workplace. Transport is the main source of $\mathrm{CO} 2$ emissions. Thus transport is becoming an important element of forming urban environment.

\section{Discussion}

We demonstrated that the transport infrastructure survey is a social and economic result of the city's management. The city leaders have real possibilities to reduce pollution and carbon 
emissions, strengthen ecosystems and minimize environmental risks. Effective planning of city districts can bring significant improvements in environmental effects. Expenditures on city infrastructure, including streets, railways, water and sewage systems, significantly go down hand in hand with the growth of city population density. Integrated strategies and innovative civil engineering technologies, use of city's power supply, potable and waste water, development of innovative transport systems minimize environmental pollution and adverse impact on environment.

Therefore the transport infrastructure congestion and related costs can be offset by effective systems of public transportation.

The developing countries still facing significant problems with transport infrastructure have an option while choosing a course of development: low emissions level or transport dependence. As a rule, the smaller the role of road network the lower are emissions of greenhouse gases. If public transport constitutes an integral part of the city transport modal structure, there is no conflict between transport sector with low emissions level, fast urban population growth and high income level.

It is imperative to pursue integrated initiatives geared at reducing the number of useless rides, low-carbon fuel, energy consumption, greenhouse gas emissions and increasing safety of passengers. This is a wide range of issues calling for a dramatic shift in transport infrastructure management, i.e. shift in our attitude toward transition from the system of "transportation means and motorways" to the integrated "network of passengers, services and conditions" of life in a megacity.

\section{Reference}

1. T.D. Auld, K.A. Keith, Ecological Management and Restoration (Special Issue: Science supporting threatened species conservation) 10, 79-87 (2009)

2. J. Broadbent, Transformations: Ecology of Pyrmont peninsula 1788 - 2008 (2010)

3. R.H. Kargon, A.P. Molella, Invented Edens: Techno-Cities of the Twentieth Century (The MIT Press, Cambridge, Massachusetts, 2008)

4. R. Register, Eco-city Berkeley: Building Cities for a Healthy Future (North Atlantic Books: Berkeley, California, 1987)

5. M. Roseland, Cities 14(4), 197-202 (1997)

6. H. Barton, Sustainable Communities: the Potential for EcoNeighbourhoods (Earthscan Publishers, London, 2000)

7. D.N. Kavtaradze, A.A. Brudny, Ciencias Sociales, 2 (1984)

8. V. Mega, Cities 17(3), 227-236 (2014)

9. J. Macedo, Cities 21(6), 537-549 (2004)

10. M. Laituri, Cities 13(5), 329-337 (1996)

11. WIT Transactions on Ecology and the Environment, WIT Press The Sustainable City VI(129), 249 (2010)

12. I.M. Smolyar, The National Doctrine of Urban Development in Russia. The concept of the town-planning policy of Russia at the beginning of the XXI century (Moscow, 2001)

13. D. Radushinsky, A. Mottaeva, L. Andreeva, G. Dyakova, IOP Conference Series: Earth and Environmental Science 90(1), 012137 (2017)

14. A. Mottaeva, IOP (Earth and Environmental Science) 90, 12117 (2017)

15. M.A. Bahauovna, M.A. Bahauovna, International Journal of Applied Engineering Research 10(23), 43446-43449 (2015) 